\title{
OTRI 2 - Effects of L-alanyl-L-glutamine media supplemen- tation on batch hybridoma growth and monoclonal antibody production
}

Guillermo Marini ${ }^{1}$; Fernando de Paiva Conte ${ }^{1 \star}$; Marcia Arissawa ${ }^{1}$.

1 - Bio-Manguinhos, Fiocruz.

Introduction:

As the demand for monoclonal antibodies $(\mathrm{mAb})$ is increasing, there is a significant interest in developing optimized cell culture processes for hybridoma. Optimization process comprises a number of variables, including the selection of better producer hybridomas, culture media and bioreactor culture conditions. L-glutamine is an unstable essential amino acid involved in hybridoma energy production, cell growth and antibody synthesis. However, L-glutamine breaks down to ammonium that can, at least, lower hybridoma growth and $\mathrm{mAb}$ production. Dipeptides of L-glutamine with L-alanine or L-glycine are stable forms, which can be used in cell culture media to avoid its negative effects.

\section{Objective:}

Evaluate the effects of L-alanyl-L-glutamine on hybridoma growth kinetics and $\mathrm{mAb}$ productivity.

\section{Methodology:}

The murine hybridoma cell line 90DA5/CB5/AA3, which produces mouse immunoglobulin (Ig) G1א against PBP2a protein, was used in a series of batch experiments performed in roller bottles during 7 days. The medium utilized was DMEM high glucose (4.5g/L; LONZA) supplemented with glutamine or L-alanyl-L-glutamine (6.4mM; Gibco) and $10 \%$ v/v fetal calf serum (FCS). Cell counts were performed in Neubauer chamber, under optical microscope, after dilution in Trypan Blue 0,4\%. After cell counting, each sample was centrifuged (200g, 10min) and the supernatant frozen for further analysis. Murine IgG (Mouse-IgG ELISA, Roche), L-glutamine (YSI2700 analyzer) concentrations were determined. Specific cell growth rate $(\mu)$ and doubling time $(\mathrm{dt})$ were calculated using the differential method, during the exponential growth phase. Specific Lglutamine consumption rate (qSglu) and IgG production rate [qP(I- 
gG)] were estimated by plotting total cell concentration, cumulative substrate consumption or production, versus the integral of viable cells (IVC) and fitting the plots with a regression coefficient of close to one.

\section{Results:}

L-alanyl-L-glutamine compared to L-glutamin- -supplemented media increased hybridoma cell growth, after 7 days, as measured by IVC (212390000 and 169267500 cell.h/mL, respectively) and extended the stationary phase $(2.05+0.13$ and $0.87+0.08 \times 106 \mathrm{cell} / \mathrm{mL}$ at $96 \mathrm{~h}$, respectively). Interestingly, it did not affect the maximum viable cell concentration $(2.70+0.17$ and $2.60+0.06$ $\mathrm{x} 106$ cells/mL at $72 \mathrm{~h}$, respectively), $\mu$ (0.023 and $0.023 \mathrm{~h}-1$, respectively) and $\mathrm{dt}$ (30 and $30 \mathrm{~h}$, respectively). In addition, free glutamine concentration during hybridoma cultivation with L-alanylL-glutamine-supplemented medium differed from glutaminesupplemented medium since it started with low levels ( 0.035 versus $1.180 \mathrm{~g} / \mathrm{L})$, peaked at $24 \mathrm{~h}(0.844$ versus $0.853 \mathrm{~g} / \mathrm{L})$ remained above control $(0.523$ versus $0.320 \mathrm{~g} / \mathrm{L})$ and both returned to basal levels at $72 \mathrm{~h}$. Of note, spontaneous release of glutamine from L-alanyl-L-glutamine was observed in cellfree medium supplemented with FBS at 4 and 37oC. After 7 days of hybridoma cultivation in batch mode, L-alanylL-glutamine-supplemented medium presented an increase of $55 \%$ in antibody volumetric productivity when compared to glutamine-supplemented medium $(70.7$ and $45.4 \mu \mathrm{g} / \mathrm{mL}$, respectively) and an increased $\mathrm{qP}(\operatorname{IgG})$ at exponential phase (6.0 versus 4.5 x10-7 $\mu \mathrm{g} / \mathrm{cell} . \mathrm{h})$.

\section{Conclusion:}

L-alanyl-L-glutamine supplementation increased the hybridoma cell growth and significantly increased antibody volumetric productivity.

Keywords: Hybridoma, IgG Production, L-alanyl-L-glutamine supplementation 